\title{
Associations of Urbanicity and Sociodemographic Characteristics with Protective Health Behaviors and Reasons for Leaving the Home During COVID-19
}

\author{
Katie Burford, Erin Dooley, Kevin Lanza and Gregory Knell
}

Background: Few data exist on the characteristics of U.S. adults' compliance with movement restrictions (i.e., "stay-at-home" orders) and protective health behaviors during the COVID-19 pandemic.

Purpose: To evaluate the associations of individual- and area-level characteristics (urbanicity) with reasons for leaving home and subsequent protective health behaviors during the COVID-19 pandemic.

Methods: A convenience sample of U.S. adults $(\mathrm{N}=2,441)$ completed a 15-minute self-report online questionnaire. Exclusion criteria included: 1) missing ZIP; 2) currently sick with COVID-19; 3) difficulty with errands; and 4) "essential service" employment. Multivariable logistic regression models estimated the odds of citing reasons for leaving home and protective health behaviors by levels of urbanicity and sociodemographic factors. Data collection and analyses were conducted between April and June 2020.

Results: The analytic sample $(n=1,374)$ was primarily Non-Hispanic white $(79 \%)$, female $(72 \%)$, urban residents (43\%), and college degree or higher (85\%). Rural residents (versus urban residents) had lower odds of wearing a mask (OR $=0.60,95 \% \mathrm{Cl}: 0.43-0.83$ ). Women (versus men) had lower odds of leaving the home for shopping (grocery: $\mathrm{OR}=0.51,95 \% \mathrm{Cl}: 0.31-0.80$; essential: $\mathrm{OR}=0.68,95 \% \mathrm{Cl}: 0.52-0.88$ ), and higher odds of social distancing $(\mathrm{OR}=2.34,95 \% \mathrm{Cl}: 1.12-4.85)$ and wearing a mask $(\mathrm{OR}=1.58$, $95 \% \mathrm{Cl}: 1.20-2.08)$. Older adults [( $\geq 50$ years) versus younger adults (18-34 years)], had higher odds of leaving home for grocery shopping $(\mathrm{OR}=2.07,95 \% \mathrm{Cl}: 1.25-3.48)$ and higher odds of wearing a mask $(\mathrm{OR}=2.02,95 \% \mathrm{Cl}: 1.42-2.91)$.

Conclusions: The differences for leaving home and protective health behaviors by age, sex, and urbanicity can be useful for future health promotion strategies to encourage best practices that limit the spread of COVID-19.

Keywords: COVID-19; Mitigation Strategies; Protective Health Behaviors; Urbanicity

\section{Introduction}

On March 13, 2020, the novel Coronavirus Disease 2019 (COVID-19) was declared a national emergency in the U.S. following the World Health Organization (WHO) characterization of the virus as a pandemic (Trump, 2020). After the national declaration, movement restrictions (i.e., "stay-at-home" or "shelter-in-place" orders) were implemented between March 19-April 7, 2020 (Silverstein, 2020). Although policies varied by state, county, and municipality, generally residents were required to stay at home, unless one's occupation was considered essential or to carry out essential services. Proximal to these statewide orders, the Centers for Disease Control and Prevention $(\mathrm{CDC})$ released recommended community mitigation strategies to reduce the risk of infection, which included

The University of Texas Health Science Center at Houston (UTHealth), US

Corresponding author: Katie Burford

(kathryn.burford@uth.tmc.edu) maintaining physical or social distance, wearing a face mask, washing hands frequently, and cleaning and disinfecting frequently touched surfaces (Allegrante, Auld \& Natarajan, 2020; CDC, 2020a). With no pharmaceutical treatments or vaccines currently available for the virus, the combination of these protective health behaviors is the only existing population-level health intervention. The objectives of these strategies are to reduce transmission rates of COVID-19 until wide-scale vaccines and effective antiviral drugs are available (Andersen et al., 2006).

Given the reliance on human behavior to reduce community transmission of COVID-19, there remains a limited understanding of the U.S. public's compliance with these protective health recommendations during state-wide orders. In one report, April 7, 2020, was identified as the peak of adherence to restrictive movement orders in the U.S., with Americans staying at home for $93 \%$ of the day (i.e., 22.3 hours) (Schaul, Mayes \& Berkowitz, 2020). Based on cell phone data, the researchers found Americans were primarily visiting parks and grocery stores when 
they did leave the home, and individuals exhibited different propensities for leaving the home based on levels of urbanicity-those living in rural areas tended to leave the home more than those living in suburban and urban areas (Schaul, Mayes \& Berkowitz, 2020). Geographic differences in health behaviors have also been observed across a variety of other health behaviors. For example, residents in rural areas have been found to generally smoke more, eat less nutritious foods, and engage in less leisure time physical activity compared to urban and suburban residents (Eberhardt \& Pamuk, 2004; Hartley, 2004). These behavioral disparities in rural health have been correlated with limited health care resources and lower socioeconomic status and may persist in COVID-19 behaviors (Hartley, 2004; Thomas, DiClemente \& Snell, 2014). Preliminary evidence exploring urban-rural differences in COVID-19 preventive behaviors among a convenience sample of Chinese residents found that rural residents were less likely to engage in preventive behaviors compared to urban residents (Chen \& Chen, 2020), however this has yet to be explored in other samples. Additionally, there is limited understanding for the differences in protective health behaviors across sociodemographic characteristics, which is needed for determining at-risk populations and developing targeted public health interventions.

Ultimately, the behavioral decisions individuals make during the pandemic are central to preventing community transmission. Despite the significance of these protective health behaviors, researchers have yet to explore how urbanicity and sociodemographic characteristics are associated with Americans' reasons for leaving the home and protective health behaviors during COVID-19 state-wide orders. Understanding these associations may help to develop policies and public health communication efforts across a variety of communities, particularly among those who are least compliant in following protective health behaviors and/or most vulnerable to the virus. Therefore, the purpose of this study was to evaluate the associations of urbanicity and sociodemographic characteristics with 1) reasons for leaving home and 2) protective health behaviors during the COVID-19 movement restriction orders among a sample of U.S. adults.

\section{Methods \\ Procedures, Recruitment, and Data Collection}

Between April 15-May 5, 2020, adults residing in the U.S. were asked to respond to an anonymous 15-minute online survey on their health and related behaviors during the COVID-19 pandemic. The survey included questions related to the variables of interest in the present study (reasons for leaving home and protective health behaviors) as well as a range of other self-reported behaviors, for example sleep quality, tobacco use, alcohol consumption, drug use, physical activity, and work productivity (Knell et al., 2020). Potential participants were recruited through the investigators' social media platforms (i.e., Twitter, Facebook, Instagram). Participants were provided a brief overview of the study, informed their participation was anonymous, that they could terminate the survey at any time, and asked for informed consent prior to completing the survey. Study data were collected and managed using REDCap electronic data capture tools hosted at the XXXXX (Harris et al., 2009). This study was approved by the Committee for the Protection of Human Subjects review board at XXXXXX (IRB number: HSC-SPH-20-0346). All procedures performed were in accordance with the ethical standards of the institutional research committee and with the Declaration of Helsinki. Additionally, this study was reported following the Strengthening the Reporting of Observational Studies in Epidemiology (STROBE) Statement guidelines (von Elm et al., n.d.).

\section{Study sample}

Approximately 47,796 social media users viewed or interacted with the social media postings during the recruitment period, of which a total of 2766 (5.8\%) agreed to participate and met the eligibility criteria (aged over 18 years and currently residing in the U.S.). After consenting, the survey was submitted by 2,441 participants. For the current study, participants were included in the analyses if they reported a stay-at-home/shelter-in-place order at the time of survey completion ( $n=1,859$ [76.2\%]). Participants were excluded from analyses if they 1) had no ZIP code $(n=26$ [1.4\%]); 2) were currently sick with COVID-19 $(n=27[1.5 \%]) ; 3)$ had a physical, mental, or emotional condition causing them serious difficulty with doing errands ( $n=39$ [2.1\%]); or 4) self-reported their employment as an "essential service" ( $n=393$ [21.1\%]). Essential service workers were excluded from these analyses due to the potential need to leave their residence for work and differences in necessity of protective health behaviors.

\section{Measures}

Reasons for Leaving Home

To assess reasons for leaving the home during COVID-19, participants were asked to check all that apply to the question, "For what reasons have you left your home during the "stay in place" order?" Responses included: 1) work, 2) grocery shopping, 3) other essential shopping, 4) exercise, and 5) walking dog. Individual responses were then coded as yes/no based upon selection.

\section{Protective Health Behaviors}

Protective health behaviors were assessed with two questions. First, participants were asked to check all that apply to the question, "If you leave your home for any reason, what do you do to protect yourself when out in public?" Responses included: 1) physical/social distancing, 2) protective mask, 3) wearing gloves, 4) using hand sanitizer, 5) using disinfectant wipes, and 6) washing hands frequently. Individual responses were then coded as yes/no based upon selection. Second, participants were asked, "On average, how many hours per day (out of 24-hours) have you remained at home during the coronavirus outbreak?" Those reporting more than 24 hours at home $(n=2)$ were recoded as missing. Histograms and frequencies were examined for hours spent at home. The median was determined as 23 hours and given this, a dichotomous variable (yes/no) was created based on those that reported spending at least 23 hours inside the home (i.e., reported 23 or 24 hours at home). Further, the 23-hour cutoff value used in this study is similar to stay-at-home orders in countries 
such as France, which allowed citizens only one hour of leave per day (DW Made for Minds, n.d.).

\section{Urbanicity}

Levels of urbanicity (urban, suburban, and rural) were based on the Department of Health and Human Services definition where urban was defined as ZIP codes where population density was over 3,000 persons per square mile; suburban was defined as ZIP codes where population density was between 1,000 and 3,000 persons per square mile; and rural was defined as ZIP codes where population density was less than 1,000 persons per square mile (Cyril, Oldroyd \& Renzaho, 2013; Department of Health and Human Services, 2003). Population density was calculated within a geographic information system (ArcGIS 10.6.1, ESRI, Redlands, CA) from 2014-2018 American Community Survey 5-year estimates for total population per ZIP Code Tabulation Area (ZCTA), and a Shapefile of ZCTAs (U.S. Census Bureau, 2018a; U.S. Census Bureau, 2019).

Sociodemographic and health-related characteristics COVID-19 sickness was self-reported based on, "Do you think you have been sick from coronavirus/COVID-19?" and for those selecting "Yes" or "Maybe", a follow-up question asking the outcome of the sickness - I have recovered, I am still sick, or I was never sick. Those selecting "I am still sick" were removed. Due to the study aims, participants who selected "Yes" to the question, "Because of a physical, mental, or emotional condition, do you have difficulty doing errands alone such as visiting a doctor's office or shopping?" were also removed prior to analyses. Additionally, participants who selected "Yes" to the question, "Is your work considered essential services'?" were also removed prior to analyses.

Sex was reported as sex at birth (male/female). Ethnicity was based on selecting Hispanic or Latino (Yes/No). Race options included: white, Black or African American, Asian, American Indian/Alaska Native, Native Hawaiian or Other Pacific Islander, and More than One Race. For these analyses, based on distribution of responses, a single race/ethnicity category was coded, as "Non-Hispanic white" or "Non-white." Non-white included Hispanic, Black or African American, Asian, American Indian/Alaska Native, Native Hawaiian or Other Pacific Islander, and More than One Race. Participants selected their current age from a continuous list (18-85 years), which was recoded into (18-24 years; 35-39 years; 50 years and older) based on distribution of responses in order to obtain adequate group sizes. Household income was measured from 'Less than $\$ 9,999$ ' to 'Over $\$ 150,000$ ' in $\$ 10,000$ category increments and subsequently categorized as $<\$ 50,000 ; \quad \$ 50,000-\$ 100,000 ; \quad \$ 100,000-\$ 150,000$; and Over $\$ 150,000$. Education was measured as 'Never attended school'; 'Grades 1-8'; 'Some high school'; 'High school graduate/GED'; 'Some college/technical school'; and 'College graduate or more.' Those selecting anything other than 'College graduate' were recoded into 'Not a college graduate.' Presence of children less than 18 years of age living in the home was measured as free response (maximum response allowed $=75$ children) and categorized as 'No' if participants responded with 0 and 'Yes' if participants responded with 1+ children. Measures of health were depressive symptom severity (categorized into 'none or mild' and 'moderate to severe'), measured by the Patient Health Questionnaire (PHQ-9) (Kroenke, Spitzer \& Williams, 2001), and number of comorbidities selected, including asthma, obesity, cancer, etc. (categorized into 'none' and 'one or more') (see Questionnaire in Replication Package for a full list of measured comorbidities).

\section{Statistical analysis}

Descriptive analyses, including frequencies, percentages, means, and standard deviations, were calculated for participant characteristics, reasons for leaving home, and protective health behaviors. Logistic regression models were used to estimate the odds [odds ratios (OR) and 95\% confidence intervals (CI)] of 1) leaving home (reasons) and 2) protective health behaviors by levels of urbanicity and participant characteristics. Each outcome (5 reasons for leaving home and 7 protective health behaviors) was modeled separately. The models were mutually adjusted for the other factors of interest (urbanicity, sex, age, education, income, children in the home, depression symptom severity, comorbidity). Variance inflation factors (VIF) $(<5)$ were used to determine the presence of multicollinearity in the fully adjusted models. Analyses were performed using the odds ratio (v1.0.2; Schratz, 2017) and car (Fox \& Weisberg, 2019) packages in RStudio version 1.2.5033 (RStudio, PBC., Boston, MA) and R version 3.6.2 (R Core Team, 2019). Research materials, data, and syntax files are available on Open Science Framework at the following link: https://osf.io/3vxpy/?view_only=3f6aef5c86184b4 2910fcd41a0afOfaf.

\section{Results}

The final analytical sample included 1,374 adults (71.7\% female, $78.8 \%$ non-Hispanic white) primarily living in Texas $(64.0 \%)$ (Table 1). Participants had a mean ( \pm stand-

Table 1: Participant characteristics of the sample $(\mathrm{N}=1374)$.

\begin{tabular}{lr} 
Characteristic & \multicolumn{1}{c}{$\begin{array}{c}\text { Total } \\
\text { \% (n) }\end{array}$} \\
\hline Urbanicity & \\
Urban & $43.2(593)$ \\
Suburban & $33.3(458)$ \\
Rural & $22.0(302)$ \\
Missing & $1.5(21)$ \\
Sex & \\
Male & $28.0(385)$ \\
Female & $71.7(985)$ \\
Missing & $0.3(4)$ \\
Race & \\
Non-Hispanic white & $78.8(1083)$ \\
Non-white & $18.6(256)$
\end{tabular}

(Contd.) 


\begin{tabular}{|c|c|}
\hline Characteristic & $\begin{array}{l}\text { Total } \\
\% \text { (n) }\end{array}$ \\
\hline Missing & $2.5(35)$ \\
\hline \multicolumn{2}{|l|}{ Age } \\
\hline $18-34$ & $30.1(414)$ \\
\hline $35-49$ & $39.2(539)$ \\
\hline 50 and older & $29.9(411)$ \\
\hline Missing & $0.7(10)$ \\
\hline \multicolumn{2}{|l|}{ Education } \\
\hline Not a college graduate & $15.3(210)$ \\
\hline College graduate or more & $84.6(1162)$ \\
\hline Missing & $0.1(2)$ \\
\hline \multicolumn{2}{|l|}{ Income } \\
\hline$<\$ 50,000$ & $10.1(139)$ \\
\hline$\$ 50,000-\$ 100,000$ & $24.5(336)$ \\
\hline$\$ 100,000-\$ 150,000$ & $24.7(339)$ \\
\hline Over $\$ 150,000$ & $38.4(537)$ \\
\hline Missing & $2.4(33)$ \\
\hline \multicolumn{2}{|l|}{ Children } \\
\hline No & $56.3(774)$ \\
\hline Yes & $42.3(581)$ \\
\hline Missing & $1.4(19)$ \\
\hline \multicolumn{2}{|l|}{ Depressive Symptom Severity } \\
\hline None/Mild & $73.1(1004)$ \\
\hline Moderate to Severe & $20.1(285)$ \\
\hline Missing & $6.2(85)$ \\
\hline \multicolumn{2}{|l|}{ Comorbidity } \\
\hline None & $58.7(807)$ \\
\hline 1 or more & $41.3(567)$ \\
\hline Missing & - \\
\hline
\end{tabular}

ard deviation) age of $42.7 \pm 14.0$ years, and the majority were college graduates $(84.6 \%)$ with $63.1 \%$ reporting a household income of $\$ 100,000$ or more. About $40 \%$ of participants were living with one or more comorbidities, such as asthma ( $n=196 ; 34.5 \%)$ and/or obesity $(n=130$; $23.0 \%)$, and $20 \%$ were categorized as living with moderate to severe depressive symptom severity.

Of the five possible reasons for leaving the home that were measured, participants reported, on average $(\mathrm{M} \pm \mathrm{SD})$, leaving their home during stay-at-home orders for $2.4 \pm$ 1.0 reasons total. The most commonly reported reasons for leaving home by respondents were grocery shopping $(88.4 \%)$ and exercise $(67.5 \%)$ (Figure 1). The models, where estimates were mutually adjusted for all factors of interest, are presented in Table 2 . Rural residents had higher odds of leaving home for work compared with urban residents $(O R=1.64,95 \%$ CI:1.03, 2.61). Women reported significantly lower odds of leaving home for work $(O R=0.56,95 \% \mathrm{Cl}: 0.38,0.85)$, grocery $(O R=0.51$, $95 \% \mathrm{Cl}: 0.31,0.80)$ and other essential shopping $(O R=$ $0.68,95 \% \mathrm{CI}: 0.52,0.88$ ) than men. The oldest age bracket had significantly higher odds for grocery shopping ( $O R$ $=2.07,95 \%$ CI:1.25, 3.48) and the middle age bracket had higher odds for leaving home for work $(O R=1.90$, 95\% CI:1.14, 3.20) compared to the youngest age bracket. Compared to college graduates, those without a college degree had significantly lower odds of leaving home for grocery shopping $(\mathrm{OR}=0.53,95 \% \mathrm{Cl}: 0.33,0.87)$ and exercise $(O R=0.69,95 \% C l: 0.49,0.98)$. Compared to the lowest income bracket, the highest income bracket had significantly higher odds for leaving home to exercise $(O R$ $=1.69,95 \% C I: 1.06,2.67)$ and for walking the dog $(O R=$ $2.33,95 \% \mathrm{Cl}: 1.46,3.80)$, and lower odds to leave for grocery shopping $(O R=0.38,95 \% C I: 0.16,0.79)$. Those with a household income between $\$ 100,000-\$ 150,000$ had significantly higher odds for leaving home for walking the $\operatorname{dog}(O R=2.40,95 \% C l: 1.49,3.94)$. There were no significant differences between those reporting a household income between $\$ 50,000-\$ 100,000$ and the lowest income bracket. Those living with one or more comorbidities had significantly lower odds of leaving home for

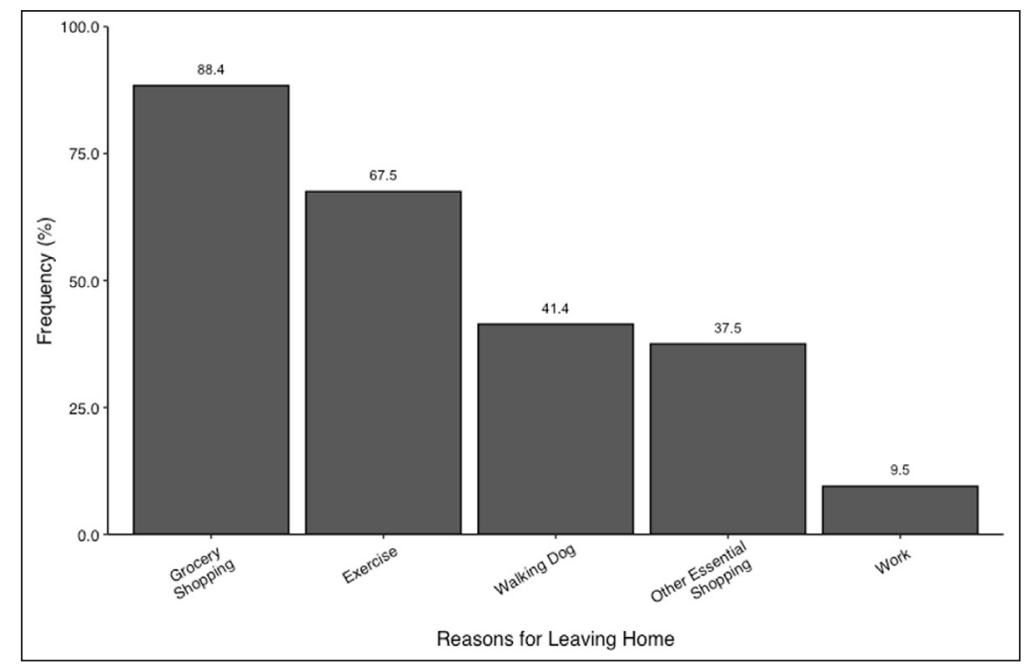

Figure 1: Prevalence of reported reasons for leaving home during COVID-19 pandemic among a convenience sample of U.S. adults, 2020. 
Table 2: Adjusted odds for reasons for leaving home during COVID-19 pandemic movement restriction orders.

Reasons for Leaving Home

\begin{tabular}{|c|c|c|c|c|c|}
\hline & \\
\hline & Grocery Shopping & Exercise & Walking Dog & $\begin{array}{l}\text { Other Essential } \\
\text { Shopping }\end{array}$ & Work \\
\hline$N=1374$ & AOR $(95 \% \mathrm{CI})$ & AOR (95\% CI) & AOR $(95 \% \mathrm{CI})$ & AOR $(95 \% \mathrm{CI})$ & AOR $(95 \% \mathrm{CI})$ \\
\hline \multicolumn{6}{|c|}{ Urbanicity $($ Referent $=$ Urban $)$} \\
\hline Suburban & $0.99(0.65,1.53)$ & $1.06(0.79,1.43)$ & $0.89(0.68,1.17)$ & $0.76(0.57,1.00)$ & $0.70(0.42,1.15)$ \\
\hline Rural & $0.89(0.56,1.46)$ & $0.77(0.56,1.07)$ & $0.78(0.57,1.06)$ & $0.95(0.70,1.30)$ & $1.64(1.03,2.61)$ \\
\hline \multicolumn{6}{|l|}{ Sex $($ Referent $=$ Male $)$} \\
\hline Female & $0.51(0.31,0.80)$ & $0.85(0.64,1.13)$ & $1.14(0.88,1.48)$ & $0.68(0.52,0.88)$ & $0.56(0.38,0.85)$ \\
\hline \multicolumn{6}{|c|}{ Age $($ Referent $=18-34$ years $)$} \\
\hline $35-49$ years & $1.52(0.96,2.40)$ & $0.79(0.56,1.09)$ & $1.12(0.83,1.53)$ & $1.04(0.76,1.42)$ & $1.90(1.14,3.20)$ \\
\hline 50 years and older & $2.07(1.25,3.48)$ & $0.77(0.54,1.09)$ & $1.08(0.78,1.49)$ & $1.31(0.94,1.81)$ & $1.14(0.64,2.03)$ \\
\hline \multicolumn{6}{|c|}{ Education (Referent $=$ College graduate or more) } \\
\hline $\begin{array}{l}\text { Not a college } \\
\text { graduate }\end{array}$ & $0.53(0.33,0.87)$ & $0.69(0.49,0.98)$ & $0.80(0.56,1.13)$ & $1.17(0.83,1.63)$ & $0.84(0.46,1.46)$ \\
\hline \multicolumn{6}{|c|}{ Household Income $($ Referent $=<\$ 50,000)$} \\
\hline$\$ 50,000-\$ 100,000$ & $0.54(0.23,1.13)$ & $1.48(0.94,2.33)$ & $1.44(0.90,2.35)$ & $0.94(0.60,1.49)$ & $1.25(0.61,2.71)$ \\
\hline$\$ 100,000-\$ 150,000$ & $0.50(0.21,1.06)$ & $1.30(0.81,2.06)$ & $2.40(1.49,3.94)$ & $1.01(0.64,1.61)$ & $0.97(0.46,2.18)$ \\
\hline Over $\$ 150,000$ & $0.38(0.16,0.79)$ & $1.69(1.06,2.67)$ & $2.33(1.46,3.80)$ & $0.98(0.62,1.55)$ & $0.79(0.38,1.79)$ \\
\hline \multicolumn{6}{|c|}{ Children $($ Referent $=\mathrm{No}$ ) } \\
\hline Yes & $1.05(0.69,1.62)$ & $1.25(0.93,1.67)$ & $0.94(0.71,1.23)$ & $1.16(0.88,1.53)$ & $0.86(0.55,1.35)$ \\
\hline \multicolumn{6}{|c|}{ Depressive Symptom Severity $($ Referent $=$ None $/$ Mild $)$} \\
\hline $\begin{array}{l}\text { Moderate to } \\
\text { Severe }\end{array}$ & $1.30(0.83,2.09)$ & $0.77(0.57,1.04)$ & $0.97(0.72,1.31)$ & $0.95(0.70,1.28)$ & $1.08(0.53,1.21)$ \\
\hline \multicolumn{6}{|c|}{ Comorbidity $($ Referent $=$ None $)$} \\
\hline 1 or More & $0.65(0.45,0.96)$ & $0.61(0.47,0.79)$ & $1.13(0.89,1.45)$ & $1.18(0.92,1.52)$ & $0.80(0.56,1.14)$ \\
\hline
\end{tabular}

CI confidence interval; OR odds ratio.

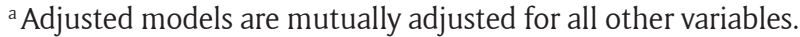

${ }^{\mathrm{b}}$ Boldface indicates statistical significance $(p<0.05)$.

grocery shopping $(O R=0.64,95 \% C I: 0.45,0.96)$ and exercise $(O R=0.61,95 \% C l: 0.47,0.79)$.

of the seven possible protective health behaviors that were measured, participants reported, on average $(\mathrm{M} \pm \mathrm{SD})$, engaging in $4.8 \pm 1.3$ behaviors total. Physical/social distancing (97.2\%) and frequent hand washing (91.8\%) were the most commonly reported behaviors by participants (Figure 2). The models, where estimates were mutually adjusted for all factors of interest, are presented in Table 3. Suburban residents had significantly greater odds $(O R=1.45,95 \%$ CI:1.08, 1.94) of spending at least 23 hours inside the home compared to urban residents. Rural residents had significantly lower odds of wearing a protective mask $(O R=0.60,95 \% \mathrm{CI}: 0.43,0.83)$ and gloves $(O R$ $=0.60,95 \% \mathrm{CI}: 0.41,0.88)$, compared to urban residents. Compared to men, women had significantly higher odds of physical/social distancing (OR $=2.34,95 \% C I: 1.12,4.85)$; washing hands frequently $(O R=1.72,95 \% C l: 1.11,2.66)$; wearing a protective mask $(O R=1.58,95 \%$ CI:1.20, 2.08); using hand sanitizer $(O R=1.48,95 \% C l: 1.09,2.00)$; and disinfectant wipes $(O R=1.82,95 \% \mathrm{Cl}: 1.40,2.36)$. Those in the oldest age bracket had significantly higher odds of using protective masks $(O R=2.02,95 \% C I: 1.42,2.91)$; disinfectant wipes $(O R=1.46,95 \% \mathrm{CI}: 1.06,2.02)$; and wearing gloves $(O R=2.63,95 \% C I: 1.81,3.85)$; however, they had significantly lower odds of using hand sanitizer (OR $=0.65,95 \% \mathrm{CI}: 0.45,0.95)$ and spending at least 23 hours inside the home $(\mathrm{OR}=0.70,95 \% \mathrm{CI}: 0.50,0.98)$, compared to the youngest age bracket. There were no significant differences between the middle age bracket and the youngest age bracket. Those without a college degree had significantly lower odds of physical/social distancing ( $O R$ $=0.41,95 \% \mathrm{CI}: 0.18,0.98$ ) than those with a college degree or more. Those with children had significantly higher odds of using disinfectant wipes $(O R=1.43,95 \% C I: 1.09,1.88)$. Participants with moderate to severe depressive symptom severity had significantly lower odds of physical/social distancing $(O R=0.37,95 \% C I: 0.17,0.84)$ compared to those with none or mild symptom severity. Finally, compared to those without a comorbidity, those with one or more had significantly higher odds of using hand sanitizer $(O R=1.39,95 \% C I: 1.03,1.88)$. No significant differences 


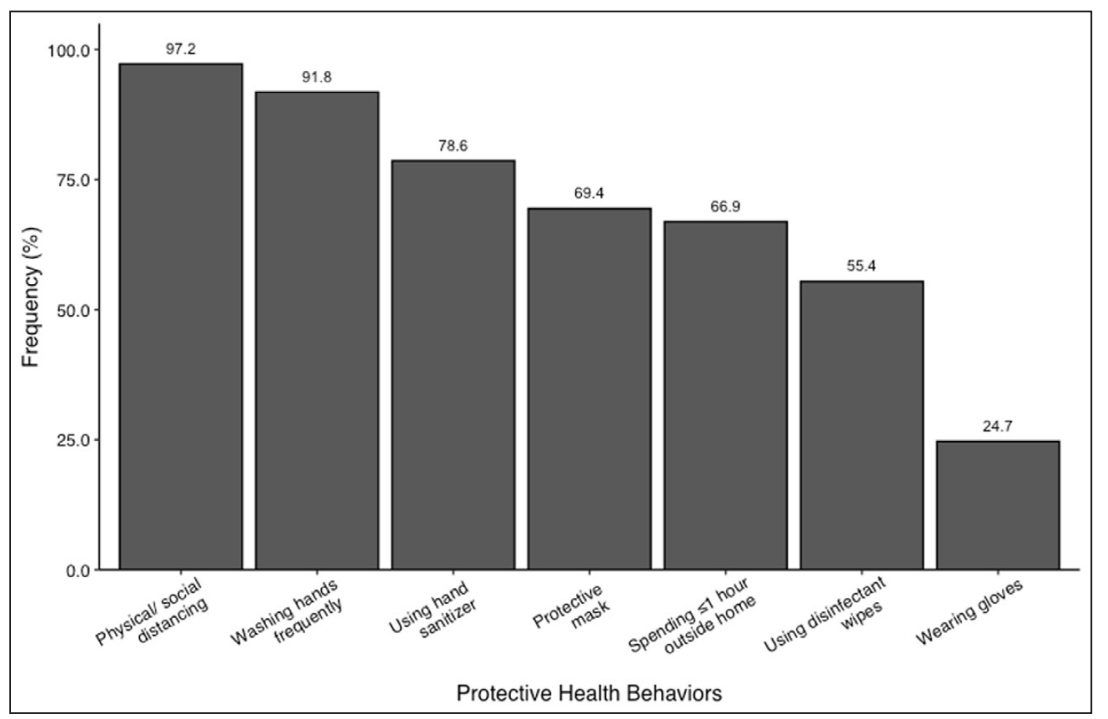

Figure 2: Prevalence of reported protective health behaviors during COVID-19 pandemic among a convenience sample of U.S. adults, 2020.

by household income for any of the measured protective health behaviors were found, when controlling for the other participants characteristics.

\section{Discussion}

During the COVID-19 movement restriction orders, the reasons for a convenience sample of U.S. adults leaving their homes and their protective health behaviors were explored. The major findings of this study were that in this sample of U.S. adults, those who were male, older, living without comorbidities, and residing in rural areas had higher odds of leaving the home. Additionally, those who were male, younger, and residing in rural areas had lower odds of enacting various protective health behaviors. These findings suggest that encouraging protective health behaviors is needed among specific sociodemographic populations including males, younger individuals, and rural communities, especially as cases rise across the U.S (CDC, 2020c).

State-wide orders were established by government officials to help mitigate the risk of COVID-19 hospitalizations by mandating individuals stay home as much as possible (Sen et al., 2020). Approximately $80 \%$ of CDC survey respondents approved of state-wide movement restriction orders (Czeisler et al., 2020). This study supports this finding as almost $70 \%$ of participants reported staying at home 23 hours or more hours per day.

Reasons for leaving the home differed by sociodemographic characteristics. Leaving home to grocery shop was reported by almost $90 \%$ of the sample, and the greatest number of differences across populations was seen for this activity. Individuals reporting household incomes of $\$ 150,000$ or more and those without a college education were less likely to report leaving home to grocery shop. The differences between household income may be due to the availability of online shopping and delivery services for those with the financial ability to do so. The use of meal delivery services increased by an estimated $70 \%$ at the end of March 2020 from the previous year (Hobbs,
2020; Savitz, 2020). For lower income and those without a college degree, lower odds of leaving to grocery shop may be due to possible use of food banks and food pantries (Feeding America, 2020). Higher levels of education have been found to be protective against food insecurity during COVID-19 (Kent et al., 2020).

Income and education categories were also associated with individuals leaving the home to exercise and/or walk their dogs. Those in the highest income and education categories, and those without a comorbidity were more likely to leave the home to exercise and/or walk their dogs. Evidence suggests that certain chronic conditions may be associated with a higher risk of COVID-19 severity and death (CDC, 2020b; Yang et al., 2020). Therefore, those with chronic conditions may have higher perceived risk of disease and subsequently stay at home more. In addition to perceived risk, the Health Belief Model suggests perceived barriers, benefits, and susceptibility are predictive of behavior change (Rosenstock, 1974). Future studies should consider including these constructs, such as perceived risk, when studying leaving home and protective health behaviors during pandemics to examine this association. Additionally, while this study only captured two types of physical activity behaviors, researchers have found the greatest reductions in walking during the early COVID-19 time period occur among those in lower income households (Dunton et al., 2020).

Individuals' protective health behaviors also varied by levels of urbanicity, sex, age, education, income, and comorbidity status. The finding that suburban residents were more likely to spend at least 23 hours inside the home compared to urban residents may be because there is typically more space available within suburban private homes than in urban areas. Generally, suburban communities are characterized by large lots with single-family detached homes and private yards (Ewing, 2008). In urban areas single-family detached homes constitute only $57.5 \%$ of all housing units with multifamily housing accounting for a large percentage of housing (32.0\%) (U.S. Census 


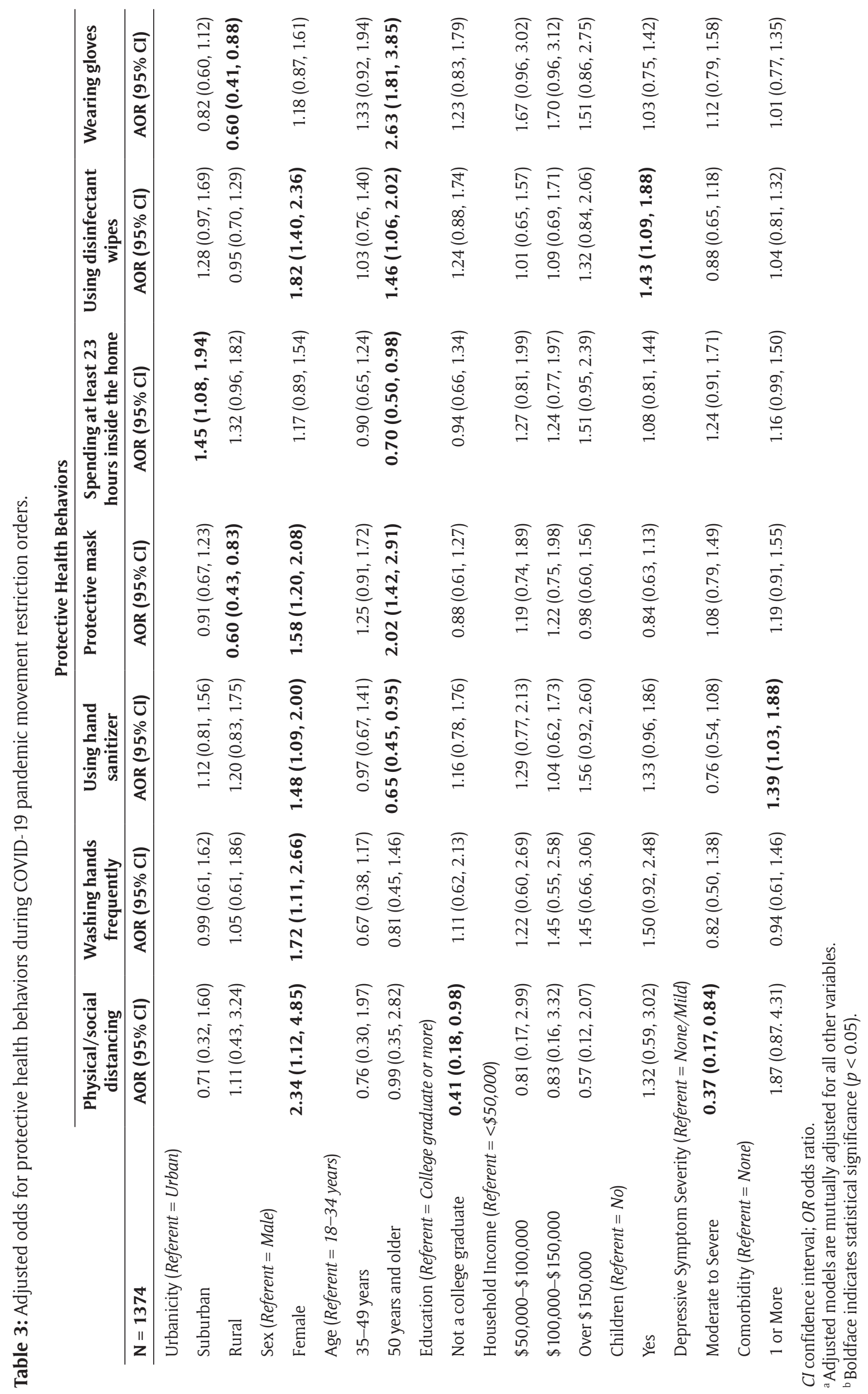


Bureau, 2018b). However, in rural areas, $77.1 \%$ of housing units are single-family detached homes (U.S. Census Bureau, 2018b). These differences in housing spaces and the lower population density may explain why rural residents were less likely to wear protective masks and gloves compared to urban residents as they may perceive their risk for COVID-19 infection as lower than those living in urban areas. As found by Chen \& Chen (2020), rural residents may evaluate the relevance of the protective health information as less salient to them than urban residents and therefore are less likely to engage in protective behaviors. Future research could also consider examining political beliefs in the context of urbanicity differences as geographical areas may have variations in majority party affiliations (Parker et al., 2018). Painter \& Qiu (2020) found that residents living in Republican counties were less likely to fully comply with movement restriction orders relative to those living in Democratic counties. Further, political conservatism has been found to mediate trust in science and compliance with COVID-19 preventive behaviors, such that those with higher political conservatism trust science to a lesser degree, and therefore have lower levels of compliance with preventive behaviors (Plohl \& Musli, 2020).

Men, younger adults, those without children, and those living without comorbidities were less likely to report protective health behaviors, although younger adults were more likely to spend at least 23 hours at home than older adults. Several of these differences could be further expanded upon by tying them to psychological factors such as risk perception and perceived susceptibility across demographic groups. Perceived susceptibility has been found to be associated with preventive behaviors, such as hand washing and mask wearing, and avoidant behaviors, such as avoiding large gatherings, during a pandemic (Bish $\&$ Michie, 2010). Additionally, COVID-19 risk perception has been shown to be associated with COVID-19 prevention guidelines compliance (Abdelrahman, 2020; Harper et al., 2020; Plohl \& Musil, 2020). Men and younger individuals have been found to engage in risky health behaviors more than their counterparts (Duell et al., 2018; Pawlowski et al., 2008). While additional research is warranted to discern the mechanisms of COVID-19 health behaviors, it may be that individuals who were more likely to use protective health behaviors in this sample perceived themselves as more susceptible to COVID-19 and therefore engaged in protective behaviors to a greater degree. Moreover, the present results are in line with a study in Hubei Province, China, which found that women and older adults in higher socioeconomic status households were most likely to wear face masks and were most knowledgeable about the importance of wearing masks (Zhong et al., 2020).

An urgent public health response is needed to increase adherence to mask wearing and maintaining physical/social distance among men, younger individuals, and in rural contexts. Evidence suggests that men have a higher risk of COVID-19 severity and death, and in states where cases are surging, younger individuals are making up a growing number of cases (Chu et al., 2020; Fox, 2020; Zheng et al., 2020). In Texas (as of late June
2020), residents under the age of 30 contributed to the majority of positive cases (Champagne \& Oxner, 2020). Additionally, the known health disparities across rural environments, such as healthcare access and critical care resources, have hindered the infectious disease response in rural communities and may result in greater mortality in these areas due to COVID-19 (Santibanez et al., 2019; Prusaczyk, 2020). Thus, national, state, and local health leaders should target their messaging around adherence to protective health behaviors towards men, younger individuals, and rural communities as this may be critical for preventing the spread and consequences of COVID-19.

\section{Limitations}

The findings of this study were from a convenience sample that was overrepresented by women, higher income, college educated, non-essential workers, and non-Hispanic white individuals. Further, individuals without online access would have been unable to participate in this webbased survey. Although most of the sample resided in Texas, participants across 39 states (+District of Columbia) were surveyed. Because these results may not be generalizable, future studies should strive to capture these behaviors in other populations. Despite this, the convenience sampling methodology allowed for an important first step in the surveillance of human behavior during a critical time period of COVID-19. The reliance of self-report for this survey might have been subject to social desirability bias; making the survey anonymous attempted to mitigate bias. In addition, there may be other sociodemographic exposures that influence protective health behaviors and reasons for leaving home (Plohl \& Musil, 2020). Additionally, including psychological exposures and measures associated with behavior change such as perceived risk, knowledge, beliefs, social context, and policy efforts in the context of COVID-19 is needed to strengthen future efforts to encourage protective health behaviors and inform public health strategies and communication efforts. Finally, the U.S. stay-at-home/shelter-in-place orders had no specific requirements for the number of hours spent at home, unlike in other countries. Therefore, using a different cutoff value may lead to different associations. However, the 23-hour cutoff value used in this study is similar to stay-at-home orders in other countries, such as France, which allowed citizens only one hour of leave per day (DW Made for Minds, n.d.).

\section{Conclusions}

As COVID-19 continues to spread across the U.S. with over 7.4 million cases and over 200,000 deaths to date, reducing the burden of disease is paramount (CDC, n.d.). We know that human behaviors enforced by mitigation policies, such as stay-at-home orders and CDC recommendations, can significantly limit the growth and impact of COVID-19 (Hsiang et al., 2020). As one of the first national surveys conducted on COVID-19 and individuals' behavior, these findings underlay the need for federal-, state-, and community-level leadership to continue encouraging protective behaviors as people travel to essential services. In addition, sustained public health response efforts should promote use and provide access to protective masks, hand 
sanitizer, and disinfectant wipes for individuals that are least likely to engage in protective health behaviors such as males, younger individuals, and those in rural areas. Clarity in health messages and developing intervention efforts involving these groups could be one strategy to mitigate the spread of the virus. Alongside determining the mechanisms behind reasons for leaving the home and protective health behaviors during COVID-19, national surveillance is desperately needed to uncover additional sociodemographic disparities in leaving the home and protective health behaviors.

\section{Competing Interests}

$\mathrm{KB}$ and $\mathrm{ED}$ disclose no funding sources. KL is supported by the Michael \& Susan Dell Foundation through the Michael \& Susan Dell Center for Healthy Living at the UTHealth School of Public Health. GK is supported by the Children's Health Foundation, Dallas, TX. The sponsors had no role in study design; collection, analysis, and interpretation of data; writing the report; and the decision to submit the report for publication. This study was not supported by external funding.

\section{Author Contribution}

Katie Burford and Erin Dooley authors contributed equally to this manuscript.

\section{References}

Abdelrahman, M. (2020). Personality traits, risk perception, and protective behaviors of Arab residents of Qatar during the COVID-19 pandemic. International Journal of Mental Health and Addiction (pp. 1-12). DOI: https://doi.org/10.1007/ s11469-020-00352-7

Allegrante, J. P., Auld, M. E., \& Natarajan, S. (2020). Preventing COVID-19 and Its Sequela: "There Is No Magic Bullet... It's Just Behaviors." American Journal of Preventive Medicine. DOI: https://doi. org/10.1016/j.amepre.2020.05.004

Andersen, L. B., Harro, M., Sardinha, L. B., Froberg, K., Ekelund, U., Brage, S., \& Anderssen, S. A. (2006). Physical activity and clustered cardiovascular risk in children:Across-sectional study(The European Youth Heart Study). The Lancet, 368(9532), 299-304. DOI: https://doi.org/10.1016/S0140-6736(06)69075-2

Bish, A., \& Michie, S. (2010). Demographic and attitudinal determinants of protective behaviours during a pandemic: A review. British Journal of Health Psychology, 15(4), 797-824. DOI: https://doi. org/10.1348/135910710X485826

Centers for Disease Control and Prevention. (n.d.). United States COVID-19 Cases and Deaths by State. Retrieved from https://www.cdc.gov/coronavirus/ 2019-ncov/cases-updates/cases-in-us.html

Centers for Disease Control and Prevention. (2020a, April 24). How to Protect Yourself \& Others. Retrieved from https://www.cdc.gov/coronavirus/2019ncov/cases-updates/cases-in-us.html

Centers for Disease Control and Prevention. (2020b, June 25). People of Any Age with Underlying Medical Conditions. Coronavirus Disease 2019
(COVID-19). Retrieved from https://www.cdc.gov/ coronavirus/2019-ncov/need-extra-precautions/ people-with-medical-conditions.html\#obesity

Centers for Disease Control and Prevention. (2020c, June 29). Trends in Number of COVID-19 Cases in the US Reported to CDC, by State/Territory. CDC COVID Data Tracker. Retrieved from https://www.cdc.gov/ covid-data-tracker/\#trends

Champagne, S., \& Oxner, R. (2020, June 16). Surge in coronavirus cases linked to more Texans in their $20 \mathrm{~s}$ getting sick, officials say. The Texas Tribune. Retrieved from https://www.texastribune.org/2020/06/16/ texas-coronavirus-spike-young-adults/

Chen, X., \& Chen, H. (2020). Differences in Preventive Behaviors of COVID-19 between Urban and Rural Residents: Lessons Learned from A Cross-Sectional Study in China. International Journal of Environmental Research and Public Health, 17(12), 4437. DOI: https://doi.org/10.3390/ijerph17124437

Chu, D. K., Akl, E. A., Duda, S., Solo, K., Yaacoub, S., Schünemann, H. J., Chu, D. K., Akl, E. A., El-harakeh, A., Bognanni, A., Lotfi, T., Loeb, M., Hajizadeh, A., Bak, A., Izcovich, A., Cuello-Garcia, C. A., Chen, C., Harris, D. J., Borowiack, E., ... Schünemann, H. J. (2020). Physical distancing, face masks, and eye protection to prevent personto-person transmission of SARS-CoV-2 and COVID19: A systematic review and meta-analysis. The Lancet, 395(10242), 1973-1987. DOI: https://doi. org/10.1016/S0140-6736(20)31142-9

Cyril, S., Oldroyd, J. C., \& Renzaho, A. (2013). Urbanisation, urbanicity, and health: A systematic review of the reliability and validity of urbanicity scales. BMC Public Health, 13(1). DOI: https://doi. org/10.1186/1471-2458-13-513

Czeisler, M. É., Tynan, M. A., Howard, M. E., Honeycutt, S., Fulmer, E. B., Kidder, D. P., Robbins, R., Barger, L. K., Facer-Childs, E. R., Baldwin, G., Rajaratnam, S. M. W., \& Czeisler, C. A. (2020). Public Attitudes, Behaviors, and Beliefs Related to COVID-19, Stay-at-Home Orders, Nonessential Business Closures, and Public Health GuidanceUnited States, New York City, and Los Angeles, May 5-12, 2020. MMWR. Morbidity and Mortality Weekly Report, 69(24), 751-758. DOI: https://doi. org/10.15585/mmwr.mm6924e1

Department of Health and Human Services. (2003). Part III, Department of Health and Human Services, Centers for Medicare \& Medicaid Services, 42 CFR Parts 403 and 408 Medicare Program; Medicare Prescription Drug Discount Card; Interim Rule and Notice. Retrieved from https://www.cms.gov/Regulations-and-Guidance/Regulations-and-Policies/QuarterlyProviderUpdates/downloads/cms4063ifc.pdf

Duell, N., Steinberg, L., Icenogle, G., Chein, J., Chaudhary, N., Di Giunta, L., Dodge, K. A., Fanti, K. A., Lansford, J. E., Oburu, P., Pastorelli, C., Skinner, A. T., Sorbring, E., Tapanya, S., Uribe Tirado, L. M., Alampay, L. P., Al-Hassan, S. M., Takash, H. M. S., Bacchini, D., \& Chang, L. (2018). Age Patterns in Risk Taking Across the World. Journal 
of Youth and Adolescence, 47(5), 1052-1072. DOI: https://doi.org/10.1007/s10964-017-0752-y

Dunton, G., Wang, S., Do, B., \& Courtney, J. (2020). Early Effects of the COVID-19 Pandemic on Physical Activity Locations and Behaviors Adults Living in the U.S: Differences by Ethnicity and Income. Cambridge Open Engage. DOI: https://doi.org/10.33774/ coe-2020-kx2rq-v2

DW Made for Minds. (n.d.). Coronavirus: What are the lockdown measures across Europe? Retrieved from https://www.dw.com/en/coronavirus-what-are-thelockdown-measures-across-europe/a-52905137

Eberhardt, M. S., \& Pamuk, E. R. (2004). The Importance of Place of Residence: Examining Health in Rural and Nonrural Areas. American Journal of Public Health, 94(10), 1682-1686. DOI: https://doi.org/10.2105/ AJPH.94.10.1682

Ewing, RH. (2008). Characteristics, Causes, and Effects of Sprawl: A Literature Review. In: J. M., Marzluff, E. Shulenberger, W. Endlicher et al. (Eds.), Urban Ecology, 519-535. Boston, MA: Springer US. DOI: https://doi.org/10.1007/978-0-387-73412-5_34

Feeding America. (2020, May 19). The Impact of the Coronavirus on Local Food Insecurity. Retrieved from https://www.feedingamerica.org/sites/default/ files/2020-05/Brief_Local\%20Impact_5.19.2020.pdf

Fox, F., \& Weisberg, S. (2019). An R Companion to Applied Regression, Third Edition. Thousand Oaks, CA: Sage. https://socialsciences.mcmaster.ca/jfox/ Books/Companion/

Fox, M. (2020, June 25). The coronavirus pandemic has moved into younger populations in US, CDC says. CNN. Retrieved from https://www.cnn. com/2020/06/25/health/coronavirus-youngerpeople-us-cdc-trnd/index.html

Harper, C. A., Satchell, L. P., Fido, D., \& Latzman, R. D. (2020). Functional fear predicts public health compliance in the COVID-19 pandemic. International journal of mental health and addiction. DOI: https:/ / doi.org/10.1007/s11469-020-00281-5

Harris, P. A., Taylor, R., Thielke, R., Payne, J., Gonzalez, N., \& Conde, J. G. (2009). Research electronic data capture (REDCap)-A metadata-driven methodology and workflow process for providing translational research informatics support. Journal of Biomedical Informatics, 42(2), 377-381. DOI: https://doi. org/10.1016/j.jbi.2008.08.010

Hartley, D. (2004). Rural Health Disparities, Population Health, and Rural Culture. American Journal of Public Health, 94(10), 1675-1678. DOI: https://doi. org/10.2105/AJPH.94.10.1675

Hobbs, J. E. (2020). Food supply chains during the COVID-19 pandemic. Canadian Journal of Agricultural Economics/Revue Canadienne d'agroeconomie. DOI: https://doi.org/10.1111/cjag.12237

Hsiang, S., Allen, D., Annan-Phan, S., Bell, K., Bolliger, I., Chong, T., Druckenmiller, H., Huang, L. Y., Hultgren, A., Krasovich, E., Lau, P., Lee, J., Rolf, E., Tseng, J., \& Wu, T. (2020). The effect of largescale anti-contagion policies on the COVID-19 pandemic. Nature. DOI: https://doi.org/10.1038/ s41586-020-2404-8

Kent, K., Murray, S., Penrose, B., Auckland, S., Visentin, D., Godrich, S., \& Lester, E. (2020). Prevalence and socio-demographic predictors of food insecurity in Australia during the COVID-19 pandemic. Nutrients, 12(9), 2682. DOI: https://doi. org/10.3390/nu12092682

Knell, G., Robertson, M. C., Dooley, E. E., Burford, K., \& Mendez, K. S. (2020). Health Behavior Changes During COVID-19 Pandemic and Subsequent "Stayat-Home" Orders. International Journal of Environmental Research and Public Health, 17(17), 6268. DOI: https://doi.org/10.3390/ijerph 17176268

Kroenke, K., Spitzer, R. L., \& Williams, J. B. W. (2001). The PHQ-9: Validity of a brief depression severity measure. Journal of General Internal Medicine, 16(9), 606-613. DOI: https://doi. org/10.1046/j.1525-1497.2001.016009606.x

Painter, M., \& Qiu, T. (2020). Political Beliefs affect Compliance with COVID-19 Social Distancing Orders. SSRN Electronic Journal. DOI: https://doi. org/10.2139/ssrn.3569098

Parker, K., Horowitz, J., Brown, A., Fry, R., Cohn, D., \& Igielnik, R. (2018, May 22). Urban, suburban and rural residents' views on key social and political issues. Retrieved from https://www.pewsocialtrends. org/2018/05/22/urban-suburban-and-rural-residents-views-on-key-social-and-political-issues/

Pawlowski, B., Atwal, R., \& Dunbar, R. I. M. (2008). Sex Differences in Everyday Risk-Taking Behavior in Humans. Evolutionary Psychology, 6(1), 147470490800600. DOI: https://doi. org/10.1177/147470490800600104

Plohl, N., \& Musil, B. (2020). Modeling compliance with COVID-19 prevention guidelines: The critical role of trust in science. Psychology, Health \& Medicine, 1-12. DOI: https://doi.org/10.1080/13548506.20 20.1772988

Prusaczyk, B. (2020). Strategies for Disseminating and Implementing COVID-19 Public Health Prevention Practices in Rural Areas. The Journal of Rural Health. DOI: https://doi.org/10.1111/jrh.12432

R Core Team. (2019). R: A language and environment for statistical computing. Vienna, Austria: R Foundation for Statistical Computing. https://www.R-project. org/

Rosenstock, I. M. (1974). Historical origins of the health belief model. Health education monographs, 2(4), 328-335. DOI: https://doi. org/10.1177/109019817400200403

Santibañez, S., Bellis, K. S., Bay, A., Chung, C. L., Bradley, K., Gibson, D., \& Shultz, A. (2019). Strengthening Rural States' Capacity to Prepare for and Respond to Emerging Infectious Diseases, 2013-2015. Southern Medical Journal, 112(2), 101-105. DOI: https://doi. org/10.14423/SMJ.0000000000000930

Savitz, E. (2020, April 24). Food Delivery Is Soaring Because of Covid-19. Why It's Still No Place to Invest. Barron's. Retrieved from https://www. 
barrons.com/articles/food-delivery-from-doordash-uber-eats-and-grubhub-is-soaring-because-ofcovid-19-51587752806

Schaul, K., Mayes, R., \& Berkowitz, B. (2020, May 6). Where Americans are still staying at home the most. Washington Post. Retrieved from https://www. washingtonpost.com/graphics/2020/national/ map-us-still-staying-home-coronavirus/

Schratz, P. (2017): R package 'oddsratio': Odds ratio calculation for GAM(M)s \& GLM(M)s, version: 1.0.2. DOI: https://doi.org/10.5281/zenodo.1095472

Sen, S., Karaca-Mandic, P., \& Georgiou, A. (2020). Association of Stay-at-Home Orders With COVID-19 Hospitalizations in 4 States. JAMA, 323(24), 2522. DOI: https://doi.org/10.1001/jama.2020.9176

Silverstein, J. (2020, April 6). 43 states now have stayat-home orders for coronavirus. These are the 7 that don't. CBS News. Retrieved from https://www. cbsnews.com/news/stay-at-home-orders-states/

Thomas, T. L., DiClemente, R., \& Snell, S. (2014). Overcoming the triad of rural health disparities: How local culture, lack of economic opportunity, and geographic location instigate health disparities. Health Education Journal, 73(3), 285-294. DOI: https://doi. org/10.1177/0017896912471049

Trump, D. (2020, March 13). Proclamation on Declaring a National Emergency Concerning the Novel Coronavirus Disease (COVID-19) Outbreak. White House. Retrieved from https://www.whitehouse. gov/presidential-actions/proclamation-declaringnational-emergency-concerning-novel-coronavirusdisease-covid-19-outbreak/

U.S. Census Bureau. (2018a). American Community Survey 5-Year Estimates. Table DP05. Retrieved from https://data.census.gov/cedsci/table?d=ACS $\% 20$ 5-Year\%20Estimates\%20Data\%20Profiles\&table= DP05\&tid=ACSDP5Y2018.DP05\&g=0040000US22

U.S. Census Bureau. (2018b). American Community Survey 5-Year Estimates. Table DP04. Retrieved from https:// data.census.gov/cedsci/table?q=ACSDP1Y2019. DP04\%20United $\% 20$ States\&g=0100000US\&tid=ACS DP1Y2019.DP04\&hidePreview=true
U.S. Census Bureau. (2019). TIGER/Line Shapefile, 2019, 2010 nation, U.S., 2010 Census 5-Digit ZIP Code Tabulation Area (ZCTA5) National. Retrieved from https:// catalog.data.gov/dataset/tiger-line-shapefile-20192010-nation-u-s-2010-census-5-digit-zip-code-tabulation-area-zcta5-na

von Elm, E., Altman, D. G., Egger, M., Pocock, S. J., Gotzsche, P. C. \& Vandenbroucke, J. P. (n.d.). The Strengthening the Reporting of Observational Studies in Epidemiology (STROBE) Statement: guidelines for reporting observational studies.

Yang, J., Zheng, Y., Gou, X., Pu, K., Chen, Z., Guo, Q., Ji, R., Wang, H., Wang, Y., \& Zhou, Y. (2020). Prevalence of comorbidities and its effects in patients infected with SARS-CoV-2:Asystematic review and meta-analysis. International Journal of Infectious Diseases, 94, 91-95. DOI: https://doi.org/10.1016/j. ijid.2020.03.017

Zheng, Z., Peng, F., Xu, B., Zhao, J., Liu, H., Peng, J., Li, Q., Jiang, C., Zhou, Y., Liu, S., Ye, C., Zhang, P., Xing, Y., Guo, H., \& Tang, W. (2020). Risk factors of critical \& mortal COVID-19 cases: A systematic literature review and meta-analysis. Journal of Infection. DOI: https://doi.org/10.1016/j.jinf.2020.04.021

Zhong, B.-L., Luo, W., Li, H.-M., Zhang, Q.-Q., Liu, X.-G., Li, W.-T., \& Li, Y. (2020). Knowledge, attitudes, and practices towards COVID-19 among Chinese residents during the rapid rise period of the COVID-19 outbreak: A quick online cross-sectional survey. International Journal of Biological Sciences, 16(10), 17451752. DOI: https://doi.org/10.7150/ijbs.45221

\section{Peer Review Comments}

Health Psychology Bulletin has blind peer review, which is unblinded upon article acceptance. The editorial history of this article can be downloaded here:

- PR File 1. Updated Full Disclosure Package Link. DOI: https://doi.org/10.5334/hpb.24.pr1

- PR File 2. STROBE Checklist. DOI: https://doi. org/10.5334/hpb.24.pr2

- PR File 3. Peer Review History. DOI: https://doi. org/10.5334/hpb.24.pr3

\footnotetext{
How to cite this article: Burford, K., Dooley, E., Lanza, K., \& Knell, G. (2020). Associations of Urbanicity and Sociodemographic Characteristics with Protective Health Behaviors and Reasons for Leaving the Home During COVID-19. Health Psychology Bulletin, 4(1), 53-63. DOl: https://doi.org/10.5334/hpb.24
}

Submitted: 17 August 2020 Accepted: 05 November 2020 Published: 19 November 2020

Copyright: ( 2020 The Author(s). This is an open-access article distributed under the terms of the Creative Commons Attribution 4.0 International License (CC-BY 4.0), which permits unrestricted use, distribution, and reproduction in any medium, provided the original author and source are credited. See http://creativecommons.org/licenses/by/4.0/. 